Copyright (C) 2014 by Academic Publishing House Researcher

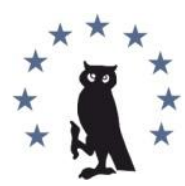

Published in the Russian Federation

European Researcher

Has been issued since 2010.

ISSN 2219-8229

E-ISSN 2224-0136

Vol. 79, No. 7-2, pp. 1351-1356, 2014

DOI: $10.13187 /$ issn.2219-8229

www.erjournal.ru

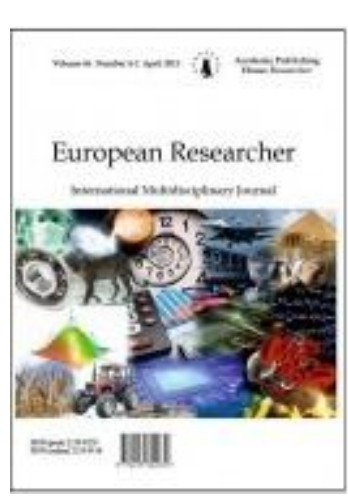

\title{
Present-Day Challenges for and Postulates of the Regional Policy of the Republic of Kazakhstan
}

Dina Orazymbetova

TOO “Astana Project”, Kazakhstan

1 VP 5 Zhaidarman St., Astana, Republic of Kazakhstan 010000

E-mail: oodi@mail.ru

Abstract. At the current stage of development, Kazakhstan's regional policy is called on to ensure the formation of favorable conditions and factors for building up the internal and external competitiveness of regions, ensuring the territorial concentration of labor and capital resources in centers of economic growth, and boosting the regional employment rate and the quality of life of the republic's citizens. This has been reflected in numerous state programs, which this article is going to examine. The author concludes that reducing the differentiation between regions is possible only through the formation of centers of economic growth.

Keywords: Kazakhstan, regional policy; hub populated locality; agglomeration; monocity; social-economic development potential; General Scheme; modernization effect; economic growth point.

\section{Introduction}

The most significant objective of modernity amid globalization is full-scale and even national development. The Republic of Kazakhstan is experiencing the situation of uneven regional development, which affects the country's competitiveness and economic growth [1]. In this regard, there is substantial significance in the role of regional programs and mechanisms for their implementation.

\section{Materials and methods}

The article's information base is made up of laws and regulations and resolutions adopted by the Government of the Republic of Kazakhstan, which set out the major focus areas for the development of regions - in particular, data from the Ministry of Regional Development of the Republic of Kazakhstan. Our input data were obtained from open-access sources - the official websites of the Ministry of Regional Development of the Republic of Kazakhstan, the Kazakh Center for Public-Private Partnership, etc. In writing this article, the author employed systemic analysis and synthesis methods.

\section{Discussion}

As one may know, the process of Kazakhstan getting its independence was accompanied by the breakdown of centers that had existed under the planned economy. This concerns monocities, collective farms, state farms, and populated localities. As a result of reforms, the country saw the 
emergence of multiple depressiveness zones, which brought about painful social processes in society (migration, degradation of infrastructure, unemployment, and social marginalization). In search of work and a better life, people started leaving villages for cities, which led to the chaotic resettlement of the population. As a result, currently the forming urban agglomerations are concentrating over a third of the country's entire population [2].

In addition to this, there is much tension around the issue of the development of villages due to lack of engineering and social infrastructure in the countryside and mass unemployment. For instance, just 108 populated localities, which accounts for $1.5 \%$ of the total number of the country's villages and townships, have sewerage in the rural locality. This is due to the fact that the major portion of sewerage networks is located in cities and rural districts with a high concentration of residents. Note that based on the standard dependable lifespan of 25 years about $66 \%$ of the republic's sewerage networks need major repairs or full replacement. The length of water conduits in the Republic of Kazakhstan is $19459.7 \mathrm{~km}$, out of which $5499.1 \mathrm{~km}$ worth of distance requires replacement and major repairs, while just $708.7 \mathrm{~km}$ has been replaced [3]. All in all, there are 60 manufacturer power-plants, 8 of which are of federal importance, 52 are regional power-plants, 22 are regional power-grid companies, out of which nearly $41 \%$ of the generating assets have been in operation for over 30 years [4]. In addition to this, many populated localities are experiencing a lack of housing, pre-school facilities, schools, health-care facilities, and potable water.

In this regard, what is topical is the issue of reforms in regional policy. The need for a new impetus to regional development in the republic was also pointed up in the Presidential Message to the people of Kazakhstan, "Let’s Build Our Future Together", dated January 28, 2011.

At the current stage of development, Kazakhstan's regional policy is called on to ensure the formation of favorable conditions and factors for building up the internal and external competitiveness of regions, ensuring the territorial concentration of labor and capital resources in centers of economic growth, and boosting the regional employment rate and the quality of life of the republic's citizens [2]. This has been reflected in numerous state programs, such as "The Development of Regions" program (No. 862; dated July 26, 2011) and "The Program for the Development of Monocities for 2012-2020" (No. 683; dated May 25; 2012), both approved by the Resolution of the Government of the Republic of Kazakhstan, "The Strategy for the Territorial Development of the Republic of Kazakhstan through to 2015" (No. 167; dated August 28, 2015) and "The Prognostic Scheme for the Country's Territorial-Spatial Development through to 2020" (No. 118; dated July 21, 2011)", both approved by the Decree of the President of the Republic of Kazakhstan, "The Major Tenets of the General Scheme for the Organization of the Territory of the Republic of Kazakhstan" (No. 1434; dated December 30, 2013) and "The Scheme for the Rational Deployment of Production Assets in the Republic of Kazakhstan" (No. 304; dated April 14, 2010), both approved by the Resolution of the Government of the Republic of Kazakhstan (No. 304; dated April 14, 2010), and others ("Ak Bulak for 2011-2020", "The Business Road Map through to 2020", "Affordable Housing-2020", "The Modernization of the Housing and Utility Sector for 20112020"), which this article is going to look into.

"The Prognostic Scheme for the Country's Territorial-Spatial Development" is a crucial tool for the country's development, which defines the state's approaches towards the key focus areas of sectoral and regional development. The primary aim of the Prognostic Scheme is to create conditions that will ensure the growth of the population's well-being based on the development and effective use of the social-economic potential of each of the country's regions and sectors. The major objectives of the Prognostic Scheme are aimed at putting together a rational system of the territorial-spatial organization of the country, which will be oriented towards the territorial concentration of people and capital in promising regions and priority growth points, intensive development of highly urbanized zones, entrepreneurial activity, and ensuring the creation of productive employment opportunities and a benign living environment for the population. In other words, the Prognostic Scheme is aimed at boosting of the population's well-being based on the rational organization and deployment of social-economic potential across the country's territory [5]. 
As part of the implementation of "The Prognostic Scheme for the Country's TerritorialSpatial Development through to 2020", there was developed "The Development of Regions" program, whose aim is to resolve topical social-economic issues to be faced by regions in the longrun. The following objectives have been set to effectuate this goal:

1. Identifying systemic issues and factors constraining the social-economic development of regions and working out an effective mechanism for the actions of executive bodies to remediate them.

2. Forming long-term centers of economic growth integrated with regional and global markets through the priority development of agglomerations centered in Astana, Almaty, Shymkent, Aktobe, and Aktau.

3. Providing financial support to regions with a view to boosting their competitiveness and the rational spatial organization of economic potential and population settlement [2].

One of the other mechanisms for the implementation of "The Prognostic Scheme for the Country's Territorial-Spatial Development through to 2020" is "The Development of Monocities" program. Its aim is to ensure the sustainable social-economic development of monocities in the mid- and long-run. In this regard, the following objectives have been set:

1. Optimizing monocities depending on the production capacity of stable enterprises.

2. Diversifying the economy and developing small and medium-sized business to ensure the optimum structure of employment for monocities' population.

3. Boosting the mobility of monocities' labor resources and stimulating voluntary moving to populated localities with high social-economic development potential and centers of economic growth.

4. Developing monocities' social and engineering infrastructure with a view to attaining the optimum population size [6].

The remarkable fact is that all of the three above programs are aimed at the development of priority growth points, such as agglomerations, 27 monocities, and promising districts. Due to the way the present-day settlement of Kazakhstan's population has been shaping out and the fact that the rural locality has a poorly developed territory infrastructure-wise, there is much significance to the concentration of production and the population.

As the world's practice indicates, the modernization effect is higher at a population density of about 40-50 people per sq. km. In Kazakhstan's current average population density is 6-8 people per sq. $\mathrm{km}$. Thus, the country is facing the objective of shifting to the polarized development of territories and formation of areals and "concentrated economic space" points in regions with the gradual attainment of desirable "economic population density" in them [5].

On the whole, in attaining the modernization effect, one can expect improvement in the competitiveness of regions through the formation of a competitive economic specialization of regions in the republican, regional, and international division of labor, which is one of the objectives of "The Prognostic Scheme for the Country's Territorial-Spatial Development".

Regions' competitiveness is defined by the extent and efficacy of the use of regions' potential (natural, raw materials, labor, and infrastructural) for the formation and operation of production facilities in the region, which would create steady and productive employment for the population.

The state has attempted more than once to determine the potential of regions and populated localities. Thus, “The Prognostic Scheme for the Country's Territorial-Spatial Development through to 2020" classifies regions by social-economic potential, demographic and labor potential, the degree to which the region's social infrastructure has been developed, the availability of healthcare facilities in the region to serve the medical needs of its residents, and the state of social and engineering infrastructure in the rural locality. For instance, regions with low development dynamics are the Zhambyl, North Kazakhstan, Akmola, and Kyzylorda regions; regions with lowerthan-medium-level development dynamics are the Kostanay, Almaty, and West Kazakhstan regions; regions with medium-level development dynamics are the Aktobe, Pavlodar, South Kazakhstan, East Kazakhstan, and Mangystau regions; regions with high development dynamics 
are the city of Astana and Karagandy Region; leader regions are Atyrau Region and the city of Almaty [5].

The Order of the First Deputy Prime Minister of the Republic of Kazakhstan - the Minister of Regional Development of the Republic of Kazakhstan (No. 235/OD; dated September 18, 2013) instituted the criteria for defining rural populated localities (RPL) with low, medium, and high social-economic development potential. Crucial classification factors assessing the potential of RPLs and the degree to which they can be regarded as promising are defined using 4 blocks of criteria: economic, engineering-infrastructural, social, and ecological, which include 22 cumulative indicators [7]. Earlier, the same criteria for identifying RPLs with low and high economic potential were instituted by the joint order of the Minister of Agriculture of the Republic of Kazakhstan (No. 28-2/430; dated July 28, 2011) and the Acting Minister of Economic Development and Trade of the Republic of Kazakhstan (No. 225; dated July 28, 2011). Thus, there are 6838 RPLs in the Republic of Kazakhstan, which are inhabited by 7.7 million residents or $45.9 \%$ of the country's total population. Out of the overall number of villages, 1 o8o can be considered as having high, 5293 medium, and 465 low development potential [8].

Based on populated localities' identified potentials and status, distance from cities or district centers, and population size, the Order of the First Deputy Prime Minister of the Republic of Kazakhstan - the Minister of Regional Development of the Republic of Kazakhstan (No. 234/OD; dated September 18, 2013) instituted the methodology for identifying hub RPLs (HRPL). HRPLs are well-developed populated localities with a developed social-engineering infrastructure, which provides a broad spectrum of state, educational, health care, financial-intermediary, culturalleisure, and maintenance services to particular groups of RPLs. HRPLs are believed to:

1) facilitate access to guaranteed state services (reducing to the optimum one the radius of social infrastructure organizations' catering to RPL residents);

2) provide for higher living standards for the population;

3) lay the groundwork for the improvement of the demographic situation;

4) boost the prestigiousness of living in the rural locality [8].

According to the Ministry of Regional Development, at the beginning of 2014 there were identified 313 hub RPLs in Kazakhstan and worked out integrated plans for their development [8].

Once the mechanism for the territorial-spatial organization of the country's territory was established, to ensure the more hands-on implementation of regional policy there were instituted by the Resolution of the Government of the Republic of Kazakhstan "The Major Tenets of the General Scheme for the Organization of the Territory of the Republic of Kazakhstan" (No. 1434; December 30, 2013). This document contains primary design solutions and suggestions concerning the organization of the territory of the Republic of Kazakhstan. The Major Tenets set out the fundamental principles and focus areas of the development of production forces settlement and deployment systems, development of social, engineering, transport, and recreation infrastructure, environmental protection, development of special urban planning control territories and facilities of federal importance. The aim of the General Scheme is to boost the quality of the population's life activity and ensure the sustainable spatial development of the territory of Kazakhstan amid the integration and globalization of global economic processes. It should be noted that this document is also aimed at the development of territories via centers of growth. The value of "The Major Tenets of the General Scheme for the Organization of the Territory of the Republic of Kazakhstan" lies in that the document addresses the following issues:

1) The issue of enhancing the existing settlement system in line with new conditions and requirements in the development of society (the migration of the rural population to cities and suburban areas without taking account of the capacity of the existing labor market and the social and engineering infrastructure of the latter; the issue of the countryside getting abandoned and neglected; the issue of the development of monocities due to high unemployment rates; the unbalancedness of the development as well as the uneven populatedness of central and suburban agglomeration zones; the issue of urbanized zones, which are plagued with environmental, transport-related, and social issues (the Shymkent and Almaty agglomeration). 
2) The issue of the rational deployment of production forces (the issue of the production of construction materials; a lack of original national biotechnological medication despite the availability of promising experimental designs).

3) The issue of the development of the social infrastructure sectors (the housing issue; the creation of the cultural sphere for people's life activity).

4) The issue of the present-day state and development of specially protected nature territories, water-protection strips and zones, territories with unique and rare landscapes and historical-cultural heritage sites.

5) The issue of ecological disaster zones (the issue of radioactive pollution across the republic's territory; the issue of managing waste in the Republic of Kazakhstan; the issue of "historical pollutions" inherited from the Soviet Union; the issue of the desertification and degradation of lands across the republic's territory), etc. [10].

A whole array of measures has been suggested to resolve these issues. These include, in addition to measures and solutions set out in "The Major Tenets of the General Scheme for the Organization of the Territory of the Republic of Kazakhstan", such state programs as "Ak Bulak for 2011-2020", "The Business Road Map through to 2020", "Affordable Housing-2020", "The Modernization of the Housing and Utility Sector for 2011-2020", "The Concept of the IndustrialInnovation Development of the Republic of Kazakhstan for 2015-2019", as well as the Law "On the Protection and Use of Historical-Cultural Heritage Sites" and other laws and strategies aimed likewise at resolving the above issues.

\section{Results and inferences}

In conclusion, we would like to underscore that the regional policy of the Republic of Kazakhstan is called on to ensure the country's economic development in terms of the territorialspatial aspect, as well as the rational deployment of production forces and improvement of the population's living standards irrespective of which region it is. The primary objective of regional policy is to iron out the more acute social and economic disproportions between the country's specific regions [11]. Due to the fact that regional development state programs are aimed at the development of economic growth centers, 465 villages with low development potential are being left out of the picture. Our analysis of state programs revealed no activities aimed at their development, although, on the whole, such programs have actually been implemented in the republic: "Ak Bulak for 2011-2020", "The Business Road Map through to 2020", "The Concept of the Industrial-Innovation Development of the Republic of Kazakhstan for 2015-2019", and others. In addition to this, it is known that programs on the development of territories are aimed at attaining the modernization effect through the development of agglomerations and hub villages. However, it should be noted that the urbanization process places a huge load on ecology and people's health and, therefore, works for smaller countries, while Kazakhstan is the world's ninthlargest country and could benefit from the rational use of this advantage. Allocating enough land without the right of sale to every Kazakh citizen for living and developing production and providing everyone with financial support can facilitate even greater economic growth for the country and greater reduction in the differentiation between its regions than using approaches related to the formation of centers of economic growth for attaining the modernization effect. However, this subject requires thorough analysis and will be addressed in detail in our next article.

\section{References}

Nurtazina, R.A., 2013. Modernization of Kazakhstan’s Regional Policy: Issues and Prospects. http://ukros.ru/wp-content/uploads/2013/11/нуртазина.doc.

The Resolution of the Government of the Republic of Kazakhstan "On Approving "The Development of Regions" Program" (No. 862; dated July 26, 2011).

The Resolution of the Government of the Republic of Kazakhstan "On Approving the Program for the Development of the Electric Power Industry in the Republic of Kazakhstan for 2010-2014" (No. 1129; dated October 29, 2010). 
The official website of the Kazakh Center for Public-Private Partnership. http://kzppp.kz/.

The Decree of the President of the Republic of Kazakhstan "On Approving the Prognostic Scheme for the Country's Territorial-Spatial Development through to 2020" (No. 118; dated July 21, 2011).

The Resolution of the Government of the Republic of Kazakhstan "On Approving the Program for the Development of Monocities for 2012-2010” (No. 683; dated May 25, 2012).

The Order of the First Deputy Prime Minister of the Republic of Kazakhstan - the Minister of Regional Development of the Republic of Kazakhstan "On Approving the Criteria for Identifying Rural Populated Localities with Low, Medium, and High Social-Economic Development Potential" (No. 235/OD; dated September 18, 2013).

The Minister of Regional Development Hosts a Conference Call. The Press Service of the Ministry of Regional Development of the Republic of Kazakhstan. http://www.nomad.su/?a=3201405220026.

The Order of the First Deputy Prime Minister of the Republic of Kazakhstan - the Minister of Regional Development of the Republic of Kazakhstan "On Approving the Methodology for Defining Hub Rural Populated Localities” (No. 234/OD; dated September 18, 2013).

The Resolution of the Government of the Republic of Kazakhstan "On Approving the Major Tenets of the General Scheme for the Organization of the Territory of the Republic of Kazakhstan" (No. 1434; dated December 30, 2013).

Davlet'yarova, G.Sh., 2011. Objectives of the Regional Policy of the Republic of Kazakhstan in the Post-Crisis Period. http://www.group-global.org/storage_manage/download_file/12314. 